CLINICAL STUDY

\title{
The early luteal phase administration of estrogen and progesterone does not induce premature luteolysis in normo-ovulatory women
}

\author{
Nicole G M Beckers ${ }^{1}$, Peter Platteau ${ }^{4}$, Marinus J Eijkemans ${ }^{2}$, Nicholas S Macklon ${ }^{5}$, Frank H de Jong ${ }^{3}$, Paul Devroey ${ }^{4}$ \\ and Bart C J M Fauser 5 \\ ${ }^{1}$ Division of Reproductive Medicine, Department of Obstetrics and Gynecology, ${ }^{2}$ Department of Public Health and ${ }^{3}$ Department of Medicine, Erasmus MC \\ University Medical Center, Dr Molewaterplein 40, 3015 GD Rotterdam, The Netherlands, ${ }^{4}$ Center for Reproductive Medicine, Dutch-Speaking Brussels \\ Free University Brussels, Laarbeeklaan 101, 1090, Brussels, Belgium and ${ }^{5}$ Department of Reproductive Medicine and Gynecology, University Medical \\ Center, Hiedelberglaan 100, 3584 CX, Utrecht, The Netherlands \\ (Correspondence should be addressed to N G M Beckers; Email: n.beckers@erasmusmc.nl)
}

\begin{abstract}
Objective: The luteal phase after ovarian hyperstimulation for in vitro fertilization (IVF) is insufficient. Therefore, luteal phase supplementation is routinely applied in IVF. It may be postulated that premature luteolysis after ovarian hyperstimulation is due to supraphysiological steroid levels in the early luteal phase. In the present study, high doses of steroids are administered after the LH surge in normo-ovulatory volunteers in order to investigate whether this intervention gives rise to endocrine changes and a shortening of the luteal phase.

Design: Randomized controlled trial.

Methods: Forty non-smoking, normal weight women, between 18 and 37 years of age, with a regular menstrual cycle (24-35 days), received either high dosages of estradiol $\left(\mathrm{E}_{2}\right)$, progesterone $(\mathrm{P}), \mathrm{E}_{2}+\mathrm{P}$ or no medication. Blood sampling was performed every other day from the day of the LH surge until $\mathrm{LH}+$ 14. Duration of the luteal phase and endocrine profiles were the main study outcomes.

Results: Early luteal phase steroid concentrations achieved by exogenous administration were comparable with levels observed following ovarian hyperstimulation for IVF. No difference in the luteal phase length was observed comparing all groups. However, a significant decrease in LH levels could be observed 6 days after the mid-cycle LH surge $(P<0.001)$ in women receiving $P$, resulting in accelerated decrease of inhibin A production by the corpus luteum $(P=0.001)$.

Conclusion: The present intervention of high-dose steroid administration shortly after the LH surge failed to induce a premature luteolysis regularly in cyclic women. It seems that the induced transient suppression in LH allowed for a timely recovery of corpus luteum function. Other additional factors may be held responsible for the distinct reduction in luteal phase length observed after ovarian hyperstimulation for IVF.
\end{abstract}

European Journal of Endocrinology 155 355-363

\section{Introduction}

During normo-ovulatory cycles, the corpus luteum remains dependent on support by the pituitary gonadotropins throughout the luteal phase (1-3). Slowing down of the gonadotropin releasing hormone (GnRH) pulse generator along with diminished luteinizing hormone (LH) pulse amplitude, is responsible for the demise of the corpus luteum both in the monkey and the human $(1,4)$. Luteolysis can only be prevented by rising doses of LH (5) or by human chorionic gonadotropin (hCG) (either exogenously administered or produced by the placenta in the case of pregnancy) (6). Under normal conditions, a tight balance is operative between negative-feedback activity of estradiol $\left(\mathrm{E}_{2}\right)$, progesterone
(P) and the periodic secretion of pituitary LH for corpus luteum support and demise $(7,8)$. Indeed, under normal conditions, luteolysis can be induced by the luteal phase administration of either GnRH agonist (9) or antagonist (10).

Since the early days of in vitro fertilization (IVF), it has been described that the luteal phase of stimulated cycles is abnormal. In fact, it was already stated in the first extended report on IVF by Edwards et al. (11) that "the luteal phase of virtually all patients was shortened considerably after treatment with gonadotropins' and it was suggested that high-follicular phase $\mathrm{E}_{2}$ levels caused by ovarian hyperstimulation might be involved. Initial studies in 1983 also confirmed the occurrence of an abnormal luteal phase in IVF cycles with the characteristic 
features of elevated P-levels along with a significantly reduced luteal phase length (12).

GnRH agonist co-treatment has been the standard of care in IVF for the prevention of a premature rise in LH during ovarian hyperstimulation (13). Typically, GnRH agonist treatment is initiated in the luteal phase of the preceding cycle and continued until the late follicular phase. Delayed pituitary recovery from downregulation during the luteal phase results in lack of support of the corpus luteum by endogenous LH and therefore in advanced luteolysis (14). The corpus luteum can be rescued under these circumstances by the administration of hCG (15) and this treatment modality became the standard of care for luteal support during the late 1980s (16). Because of the association between hCG and ovarian hyperstimulation syndrome (17), luteal phase hCG support has been largely replaced by luteal phase $\mathrm{P}$ supplementation $(18,19)$.

Attempts to secure pituitary recovery during the luteal phase by the early follicular phase cessation of $\mathrm{GnRH}$ agonist treatment $(20,21)$ failed, presumably due to the prolonged recovery of LH secretion (22). Because of the rapid recovery of pituitary gonadotropin release after discontinuation of $\mathrm{GnRH}$ antagonist $(23,24)$, it has been widely speculated that the luteal phase supplementation may not be required following ovarian hyperstimulation in combination with late follicular phase co-administration of GnRH antagonist (25). Preliminary observations in intrauterine insemination seem to favor this contention (26). However, various studies in IVF applying GnRH antagonist co-treatment have now clearly established that luteolysis is also initiated prematurely under those conditions resulting in a significant reduction in luteal phase length and greatly compromised chances for pregnancy $(27,28)$. More detailed studies could confirm that early- and mid-luteal phase $\mathrm{LH}$ levels remained suppressed following the follicular phase administration of $\mathrm{GnRH}$ antagonist $(28,29)$.

Alternative mechanisms involved in luteal dysfunction following ovarian hyperstimulation in IVF may be proposed: (i) follicle puncture and the removal of cumulus-oocyte complexes including large quantities of surrounding granulosa cells (which form the most important $\mathrm{P}$ secreting unit in the subsequent corpus luteum). However, initial studies addressing this issue failed to consistently show detrimental effects (30). (ii) Short-loop feedback by the late follicular phase bolus dose of hCG to induce final oocyte meiotic maturation. Although there were some indications of such an effect at the pituitary level suppressing gonadotropin release (31), this could not be confirmed by subsequent studies $(28,29)$. (iii) Luteal phase defects can also be induced by stimulating multi-follicle development in normo-ovulatory volunteers (even without follicle aspiration), suggesting a correlation with the development of multiple follicles itself (32).

Collectively, we postulated that high early luteal phase steroid concentrations could induce advanced luteolysis due to massive negative feedback resulting in greatly suppressed LH secretion $(33,34)$. The stimulation of multiple dominant follicles during the follicular phase will subsequently give rise to multiple corpora lutea, all involved in luteal phase steroid synthesis. The present study in volunteers was undertaken to explore further the role of early luteal phase steroids in the regulation of pituitary LH release and corpus luteum function. These findings may be relevant for the better understanding of luteal phase dysfunction following ovarian hyperstimulation for IVF.

\section{Materials and methods}

\section{Subjects}

This prospective randomized two-center trial was approved by the local ethics review committees of both participating centers (Erasmus MC Rotterdam, The Netherlands (EMC) and AZ-VUB Brussels (VUB)). An information form was sent to responders of advertisements. Subjects interested in participating underwent initial screening before enrollment in the study. A signed written informed consent was obtained from all study participants. Women who completed the study were paid for their participation. Inclusion criteria were: (i) regular menstrual cycle (cycle length between 24 and 35 days), (ii) normal body weight (body mass index $18-28 \mathrm{~kg} / \mathrm{m}^{2}$ ), (iii) reproductive age (18-37 years), (iv) normal early follicle-stimulating hormone (FSH) level ( $\leq 10 \mathrm{IU} / \mathrm{l})$, (v) absence of factor V Leiden mutation, (vi) no use of oral contraceptive or other hormone-related contraceptives in the previous 3 months, (vii) no smoking habit, (viii) no history of epilepsy, diabetes, gastrointestinal, hepatic, renal, or pulmonary disease, (ix) no use of other investigational drugs within 3 months prior to the study, or hormonal preparations within 1 month prior to the study, and finally (x) no use of anti-depressive drugs.

\section{Study protocol}

The initial screening comprised of a medical history and a physical examination, including vital signs and vaginal ultrasound examination to exclude abnormalities in both uterus and ovaries. Blood was taken for the assessment of FSH and factor V Leiden mutation (to exclude women with an increased risk for thromboembolic processes). After successful screening, the volunteers enrolled in the study.

In cycle 1, daily LH tests (Rapi Test, Orange Medical, Tilburg, The Netherlands) were performed in urine at home starting on cycle day 9 to detect the LH surge (only performed by the 25 women in the EMC). The reason for performing these LH tests was to evaluate the duration of the untreated spontaneous luteal phase. In 
cycle 2, subjects started the LH tests again on cycle day 9. On the day, the LH test became positive (confirmed with a rapid serum LH assay at the VUB), randomization took place for one of the four treatment groups. In cases where the urinary LH test was unclear, an ultrasound scan was performed at the EMC to establish the presence of a preovulatory follicle.

In order to be able to discriminate the effect of the separate steroids as well as the combined effect, this randomized study was designed to include four arms: $\mathrm{E}_{2}, \mathrm{P}, \mathrm{E}_{2}+\mathrm{P}$, and no treatment. For both centers, a separate stratified randomization list was generated by computer. Randomization took place by means of sealed envelopes for one of the four groups (see also Fig. 1). $\mathrm{E}_{2}$ group: 8 Fem 7 patches $\left(\mathrm{E}_{2} 0.1 \mathrm{mg} / \mathrm{cm}^{2}\right.$; Merck) applied on the buttocks on the day of the observed LH surge combined with four puffs $(600 \mu \mathrm{g})$ aerodiol (estrogen $150 \mu \mathrm{g} / \mathrm{spray}$; Servier, Leiden, The Netherlands) every $3 \mathrm{~h}$ on the day of LH. The patches were removed after the blood sampling on day $\mathrm{LH}+4$. $\mathrm{P}$ group: Prontogest i.m. injections ( $\mathrm{P}$ ampoules, $100 \mathrm{mg} / \mathrm{ml}$; AMSA, Rome, Italy). Started on day $\mathrm{LH}+4$ : evening $25 \mathrm{mg}, \mathrm{LH}+5$ : morning $100 \mathrm{mg}$ and evening $150 \mathrm{mg}$, and $\mathrm{LH}+6$ : morning $300 \mathrm{mg}$ and evening $300 \mathrm{mg}, \mathrm{E}_{2}+\mathrm{P}$ group: combination of the above-mentioned regimens; non-treatment group: no medication.

Blood sampling was performed every other day starting on the day of the positive $\mathrm{LH}$ test until $\mathrm{LH}+14$.

\section{Justification of interventions}

The $\mathrm{E}_{2}$ intervention was performed earlier in the luteal phase (day $\mathrm{LH}$ until day $\mathrm{LH}+4$ ) followed by the $\mathrm{P}$ intervention (day $\mathrm{LH}+4$ until day $\mathrm{LH}+6)$. In the $\mathrm{E}_{2}$ group, we intended to increase the early luteal phase $\mathrm{E}_{2}$ levels from $800 \mathrm{pmol} / \mathrm{l}$ (unstimulated situation (35)) to $5000 \mathrm{pmol} / \mathrm{l}$ (observed during IVF treatments (28)). In IVF patients, the $\mathrm{E}_{2}$ levels rise during the follicular phase to maximum levels on the day of hCG (21). From that day onwards, the $\mathrm{E}_{2}$ serum levels decrease to lower levels at day 4 after hCG. 1 Fem 7 patch increases $E_{2}$ levels to $600 \mathrm{pmol} / \mathrm{l}$ (36). Therefore, eight patches were applied on day of the positive LH test, which would give a $C_{\text {max }}$ of $4800 \mathrm{pmol} / \mathrm{l}$ after $16-24 \mathrm{~h}$. When this $C_{\max }$ and serial serum levels described earlier in a pharmacokinetic study (36) were taken into account, it could be expected to reach the following median $\mathrm{E}_{2}$ levels: $4800 \mathrm{pmol} / \mathrm{l}$ on day $\mathrm{LH}+1,2000 \mathrm{pmol} / \mathrm{l}$ on day $\mathrm{LH}+$ 2, 1800 on day $\mathrm{LH}+3$, and $1500 \mathrm{pmol} / \mathrm{l}$ on day $\mathrm{LH}+4$. As the patches were attached on the day of positive $\mathrm{LH}$ test, the $\mathrm{E}_{2}$ levels on that same day would be slowly increasing $\left(C_{\max }\right.$ is only reached after $\left.16-24 \mathrm{~h}\right)$. In order to reach high- $\mathrm{E}_{2}$ levels on the day of $\mathrm{LH}$, patches were combined with four puffs $(600 \mu \mathrm{g})$ of aerodiol nasal spray. One dose of $300 \mu \mathrm{g}$ aerodiol increases the $\mathrm{E}_{2}$ level to $5000 \mathrm{pmol} / \mathrm{l}$ after $20 \mathrm{~min}$. The initial half-life is $18 \mathrm{~min}$, the second half-life is $4 \mathrm{~h}(37)$. It can be expected to reach levels of around $10000 \mathrm{pmol} / \mathrm{l}$.

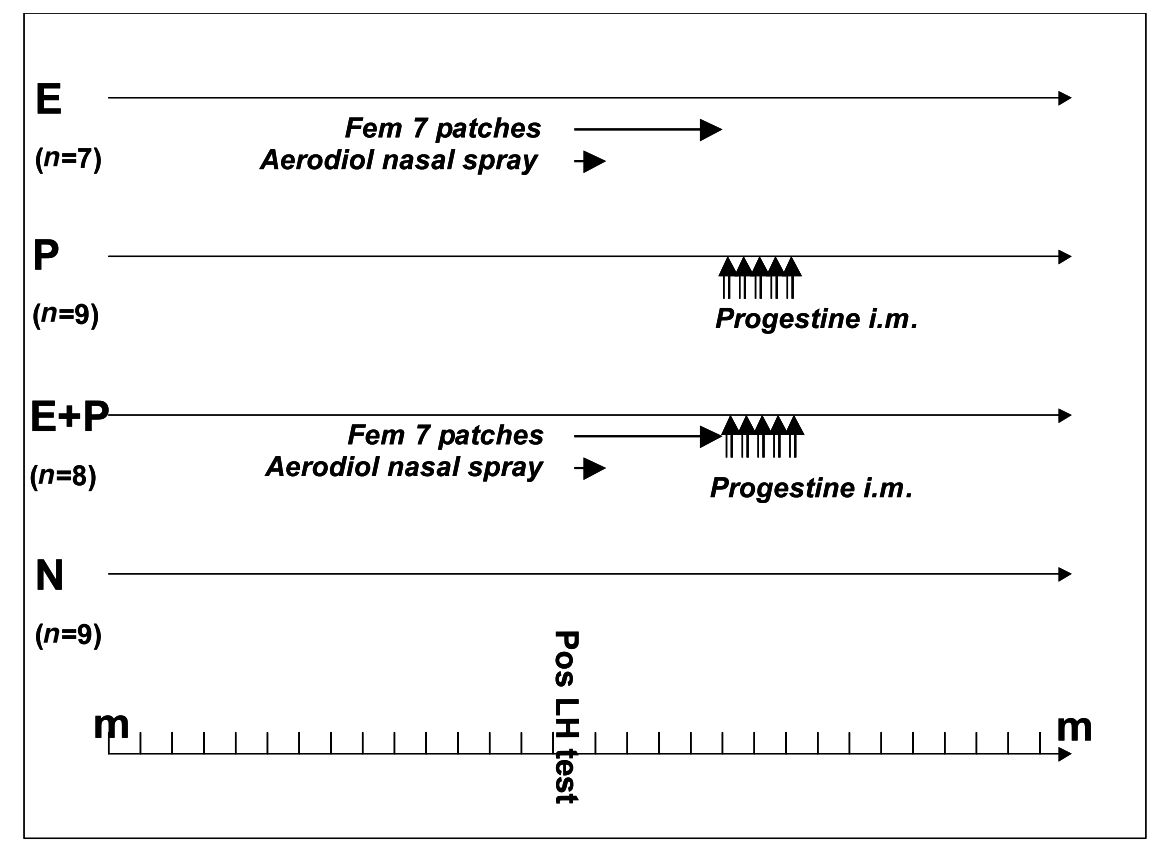

Figure 1 Schematic representation of the study protocol. Subjects performed urinary luteinizing hormone (LH) tests at home. On the day of a positive LH test, randomization took place for either estradiol $\left(E_{2}\right)(600 \mu \mathrm{g}$ aerodiol every $3 \mathrm{~h}$ on the day of LH combined with 8 Fem 7 patches from day LH until LH+4); progesterone (P) (progestine on day of $\mathrm{LH}+4: 25 \mathrm{mg}, \mathrm{LH}+5: 100$ and $150 \mathrm{mg}, \mathrm{LH}+6: 300 \mathrm{and} 300 \mathrm{mg}$ ), $\mathrm{E}_{2}+\mathrm{P}$ (combination of the above-mentioned regimens) or controls (non-treatment, $\mathrm{N}$ ) group. Blood was sampled every other day during the luteal phase. 
In the $\mathrm{P}$ group, we intended to increase $\mathrm{P}$ levels from $60 \mathrm{nmol} / \mathrm{l}$ (unstimulated situation) to $800 \mathrm{nmol} / \mathrm{l}$ (observed during IVF treatment (28)). P serum levels start to rise on day 4 after hCG, reaching maximum levels on day 6 and decreasing to low levels on day 10 $(21,28)$. The only pharmacokinetic data available in the literature were obtained from oocyte donation patients using $\mathrm{P}$ injections $50 \mathrm{mg}$ twice a day for a longer time. The maximum concentration reached in the steady-state situation was $120 \mathrm{nmol} / \mathrm{l}$ (38). These data were used to calculate the dosages needed to reach the desired situation. The expected concentrations with the above-described regimen were $100 \mathrm{nmol} / \mathrm{l}$ on day $\mathrm{LH}+4,300 \mathrm{nmol} / \mathrm{l}$ on day $\mathrm{LH}+5$, and $700-800 \mathrm{nmol} /$ l on $\mathrm{LH}+6$.

\section{Hormone assays}

Blood samples were centrifuged, and serum was frozen and stored at $-20^{\circ} \mathrm{C}$. Serum was assayed for FSH, LH, $\mathrm{E}_{2}, \mathrm{P}$, and inhibin $\mathrm{A}$ in the same laboratory (EMC). From each patient, hormone assays were performed in the same run. FSH, LH, and P measurements were performed by immunofluorometric assay (Immulite 2000; Diagnostic Products Corp., Los Angeles, CA, USA). $\mathrm{E}_{2}$ measurements were acquired by RIA (Coat-a-count; Diagnostic Products Corp.) and inhibin A was measured by inhibin A: immuno-enzymometric assay, obtained from Serotec (Oxford, UK). Intra- and interassay coefficients of variation were $<5$ and $<8 \%$ for FSH, $<$ 3 and $<6 \%$ for $\mathrm{LH},<6$ and $<16 \%$ for $\mathrm{P},<5$ and $<7 \%$ for $\mathrm{E}_{2}$, and $<8$ and $<15 \%$ for inhibin A respectively.

\section{Statistical analysis}

The endpoint of this study was luteal phase characteristics in the four different groups. The particular endpoint used for power calculation was the duration of the luteal phase. The three different treatment groups were compared with the non-treatment control. In a previous study from our group involving IVF patients undergoing ovarian hyperstimulation combined with a GnRH antagonist and a GnRH agonist bolus for final oocyte maturation, we observed a mean duration of the luteal phase of 9.6 ( \pm 3.3 days) in the absence of luteal phase supplementation (28). It was assumed that the mean duration of the luteal phase in the control group would be 14 days. To test the hypothesis whether the exposure of volunteers to high levels of either $\mathrm{E}_{2}, \mathrm{P}$ or both leads to a reduction in luteal phase length of at least 4 days, $80 \%(\beta)$ power at a $P$-value of 0.05 (twosided $\alpha=0.025$ ), nine patients were needed for each group, i.e. a total of 36 patients.

Differences among the four groups in length of the luteal phase were tested by ANOVA. To assess the differences in luteal phase endocrine profiles, the area under the curve (AUC) was calculated from the day of a positive $\mathrm{LH}$ test until the day $\mathrm{LH}+14$. Differences in
AUCs among the four groups were tested by the nonparametric Kruskall-Wallis test, because the AUCs had highly skewed distributions. In order to assess the exact influence of the administered steroids on the LH levels in the mid-luteal phase, the LH levels were also analyzed for each separate day. It was chosen to focus on day $\mathrm{LH}+4$ until day $\mathrm{LH}+10$ as the mid-luteal phase. LH levels were considered the most relevant with respect to the induction of luteolysis. ANOVA analyses were performed to test for any difference among the four groups $(n=33)$. Furthermore to be able to differentiate between the separate influence of $E_{2}$ and $P$, the analyses were repeated after rearranging the subjects into two groups twice: supplemented with $\mathrm{E}_{2}(n=15)$ or not $(n=18)$ and supplemented with $\mathrm{P}(n=17)$ or not $(n=16)$.

\section{Results}

One-hundred and seventy-nine women responded to advertisement and received a written information form. After reading this, 56 women decided to participate. The main reason for women deciding not to participate was unwillingness to be treated with high dosages of steroids. Fifty-six women underwent the initial screening and finally 40 enrolled in the study.

It turned out that the results of the urinary LH tests were not completely reliable. In retrospect (evaluating the LH levels), it became clear that six women were randomized (on the day the LH test turned out 'positive'), while their LH levels were actually below $10 \mathrm{IU} / \mathrm{l}$. In addition, one volunteer did not reach postovulatory $\mathrm{P}$ levels in the untreated group. As this protocol was intended as a mechanistic study rather than an intention to treat study, these women were excluded from further analysis. The prerandomization characteristics such as age, cycle length, body mass index, and early follicular FSH were not different among the four groups (data not shown).

Results on the duration of the luteal phase are shown in Table 1. There was no difference in duration of the luteal phase among the four groups. Moreover, in the subjects who also performed the LH tests in the normal cycle preceding the intervention cycle $(n=19)$, there was no difference in duration of the luteal phase between the normal and the study cycles (data not shown).

Endocrine profiles are depicted in Fig. 2. The expected median $\mathrm{E}_{2}$ levels were $4800 \mathrm{pmol} / \mathrm{l}$ on day $\mathrm{LH}+1$, $2000 \mathrm{pmol} / \mathrm{l}$ on day $\mathrm{LH}+2,1800$ on day $\mathrm{LH}+3$, and $1500 \mathrm{pmol} / \mathrm{l}$ on day $\mathrm{LH}+4$ (see also Materials and methods section). Blood sampling was performed every other day, thus we could only compare the expected and the assessed median levels on day $\mathrm{LH}+2$ which was $2470 \mathrm{pmol} / \mathrm{l}$ (range 1310-4105 pmol/l) and on day LH+ 4 which was $1400 \mathrm{pmol} / \mathrm{l}$ (range 596-2564 pmol/l) in subjects treated with $E_{2}$ and $E_{2}+P$. These levels were indeed in the expected range. 
Table 1 Clinical data (median and ranges) of the 33 normo-ovulatory volunteers randomized for either $E_{2}(600 \mu g$ aerodiol every $3 \mathrm{~h}$ on the day of LH combined with 8 Fem 7 patches from day LH until LH+4), P (progestine on the day of LH+4: $25 \mathrm{mg}, \mathrm{LH}+5: 100 \mathrm{and} 150 \mathrm{mg}$, $\mathrm{LH}+6: 300$ and $300 \mathrm{mg}$ ), $\mathrm{E}_{2}+\mathrm{P}$ (combination of the above-mentioned regimens) or no-treatment (controls).

\begin{tabular}{|c|c|c|c|c|c|}
\hline & $E_{2}$ & $\mathbf{P}$ & $E_{2}+P$ & Controls & $P$-value* \\
\hline $\begin{array}{l}\text { Duration of the luteal } \\
\text { phaset non-intervention } \\
\text { cycle (days) }(n=19)\end{array}$ & $21(14-22)$ & $14(12-15)$ & $14(12-17)$ & $14(13-19)$ & ns \\
\hline $\begin{array}{l}\text { Duration of the luteal } \\
\text { phase }{ }^{\text {intervention }} \\
\text { cycle (days) }(n=33)\end{array}$ & $15(13-16)$ & $14(11-17)$ & $15(13-17)$ & $14(12-17)$ & ns \\
\hline
\end{tabular}

*ANOVA. †Only volunteers in one center (EMC) performed urinary LH tests in the untreated cycle, three women were not able to detect the LH surge in the untreated cycle. ns, not significant.

After pharmacokinetic calculations regarding $\mathrm{P}$ levels, using the little data available (38) it was expected to reach $100 \mathrm{nmol} / \mathrm{l}$ on the evening of $\mathrm{LH}+$ $4\left(C_{\max }\right.$ was reached after $\left.2 \mathrm{~h}\right), 300 \mathrm{nmol} / \mathrm{l}$ on day $\mathrm{LH}+5$, and $700-800 \mathrm{nmol} / \mathrm{l}$ on day $\mathrm{LH}+6$. The assessed median $\mathrm{P}$ levels on day $\mathrm{LH}+6$ were $216 \mathrm{nmol} / \mathrm{l}(114-1040 \mathrm{nmol} / \mathrm{l})$ in patients receiving either $\mathrm{P}$ or $\mathrm{P}+\mathrm{E}_{2}$.
The AUC calculated from the day of a positive LH test until day LH +14 (see Table 2) was not different for LH among the four groups. However, as discussed in the Materials and methods section, the median LH levels were analyzed on separate days namely day $\mathrm{LH}+4$ until day $\mathrm{LH}+10$ both in subjects supplemented with $\mathrm{E}_{2}$ and not and in subjects supplemented with $\mathrm{P}$ and not. Results of this analysis are shown in Table 3. LH levels

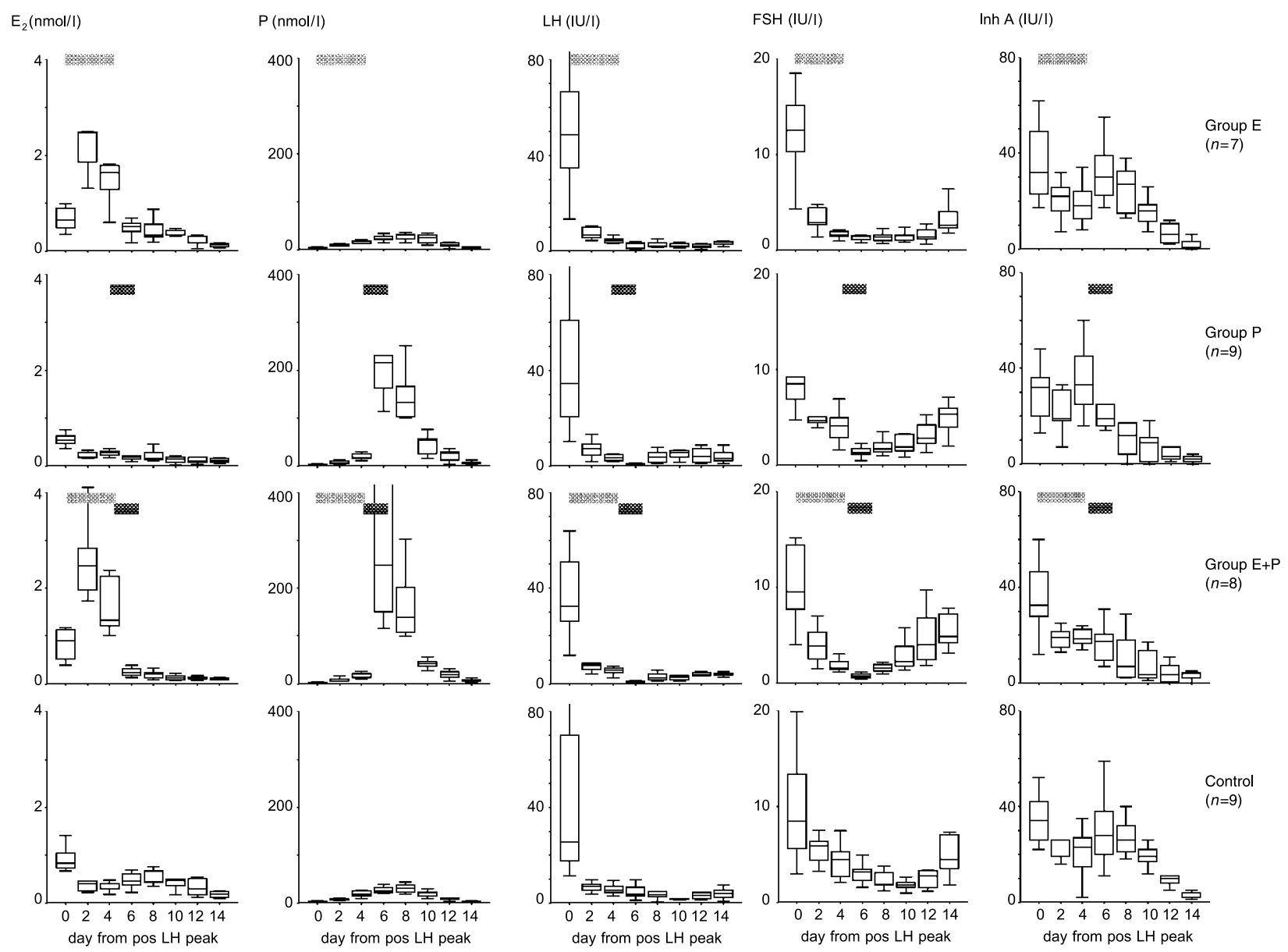

Figure 2 Box (median values and 25th and 75th percentiles) and whisker $\left(P_{5}\right.$ and $\left.P_{95}\right)$ plots representing $E_{2}, P$, follicle-stimulating hormone, $L H$ and inhibin $A$ ( $I n h A)$ serum concentrations in 33 subjects randomized for the administration of either high dosages of $E_{2}$ ( or no medication (controls) in the early luteal phase. On the $x$-axis, the days of blood sampling. pos, positive. 
Table 2 Area under the curves (AUCs) (median and ranges) of $E_{2}, P, L H$, follicle-stimulating hormone (FSH), and inhibin $A$ in 33 volunteers randomized for either $\mathrm{E}_{2}(600 \mu \mathrm{g}$ aerodiol every $3 \mathrm{~h}$ on the day of $\mathrm{LH}$ combined with 8 Fem 7 patches from day $\mathrm{LH}$ until $\mathrm{LH}+4), \mathrm{P}$ (progestine on the day of $\mathrm{LH}+4: 25 \mathrm{mg}$, $\mathrm{LH}+5: 100$ and $150 \mathrm{mg}, \mathrm{LH}+6: 300$ and $300 \mathrm{mg}$ ), $\mathrm{E}_{2}+\mathrm{P}$ (combination of the above-mentioned regimens) or no treatment.

\begin{tabular}{lccccc}
\hline & $\mathbf{E}_{\mathbf{2}}(n=7)$ & $\mathbf{P}(n=9)$ & $\mathbf{E}_{\mathbf{2}}+\mathbf{P}(n=8)$ & No treatment $(n=9)$ & $\boldsymbol{P}$-value $\dagger$ \\
\hline $\mathrm{E}_{2}(\mathrm{pmol} / \mathrm{l})$ & $9052(5902-12865)$ & $2221(1421-12865)$ & $6320(5444-10018)$ & $4033(3039-8978)$ & $<0.001$ \\
$\mathrm{P}(\mathrm{nmol} / \mathrm{l})$ & $221(115-276)$ & $961(641-2363)$ & $1193(641-1668)$ & $252(157-287)$ & $<0.001$ \\
$\mathrm{FSH}(\mathrm{IU} / \mathrm{l})$ & $21.4(11.1-37.0)$ & $35.2(20.2-51.8)$ & $29.2(24.0-62.8)$ & $42.4(23.7-57.0)$ & 0.03 \\
$\mathrm{LH}(\mathrm{IU} / \mathrm{l})$ & $41.0(31.4-65.8)$ & $51.6(29.5-60.8)$ & $45.5(26.9-82.6)$ & $47.2(23.7-144.2)$ & $\mathrm{ns}$ \\
$\mathrm{Inhibin} \mathrm{A} \mathrm{(IU/I)}$ & $218(117-323)$ & $158(120-573)$ & $118(69-252)$ & $250(155-449)$ & $\mathrm{ns}$ \\
\hline
\end{tabular}

*Kruskall-Wallis. †The AUCs were calculated from the day of positive LH surge until day LH+14. ns, not significant.

were significantly different between the groups 6 days after the mid-cycle LH surge $(P<0.001)$. This difference was associated with the administration of $\mathrm{P}(P<0.001)$, but not $\mathrm{E}_{2}(P=0.16)$.

The AUC calculated from the day of a positive LH test until LH +14 (see Table 2) was significantly different for FSH comparing the four groups $(P=0.03)$. In the $\mathrm{E}_{2}$-supplemented subjects, the suppression of the FSH levels was more pronounced compared with the P-supplemented subjects. As the influence of FSH on the corpus luteum was expected to be low, the daily analysis as performed for LH was not carried out for FSH.

The AUC calculated from the day of the positive LH test until $\mathrm{LH}+14$ (see Table 2) was not different for inhibin A comparing the four groups. However, the decrease of inhibin A production was significantly different in subjects with LH levels $\leq 1 \mathrm{IU} / \mathrm{l}$ on day $\mathrm{LH}+6(n=13)$ compared with subjects with LH levels $>1$ IU/l $(n=20 ; P=0.001$; see Fig. 3$)$.

\section{Discussion}

The present study was designed to assess whether the supraphysiologic steroid levels observed during the early luteal phase after ovarian hyperstimulation for IVF are to be held responsible for the premature luteolysis and the reduced luteal phase length. The present study showed that the administration of $\mathrm{E}_{2}$ or $\mathrm{P}$ (or both) in the early luteal phase in normo-ovulatory volunteers did not result in a shortening of the duration of the luteal phase.

Previous studies demonstrated that in IVF patients to whom no luteal support was provided, the endogenous $\mathrm{P}$ production was much higher compared with normoovulatory controls. This has been demonstrated both in the so-called long protocol (21) as well as with the use of a GnRH antagonist co-treatment (28). In the latter study, P levels were decreasing already from day 6 after hCG, presumably because the corpora lutea were depending on the hCG which had been injected $35 \mathrm{~h}$ before oocyte retrieval and subsequently cleared from the circulation around 8 days after injection. As the exogenous hCG disappeared, luteolysis occurred (and $\mathrm{P}$ production stopped) supposedly due to insufficient support by endogenous LH. In support of that hypothesis, we found a positive correlation between the AUC of LH and the AUC of P. Moreover, we previously found a positive correlation between the $\mathrm{E}_{2}$ levels on the day of $\mathrm{hCG}$ and the duration of the luteal phase (28). It has been suggested that in IVF patients, the supraphysiologic levels of $E_{2}$ or $P$ produced by multiple corpora lutea in the early luteal phase, results in a profound negative feedback at the hypothalamicpituitary level resulting in severely suppressed endogenous LH production.

In the present study, we attempted to mimic the endocrine situation of the early luteal phase as found in IVF patients in normo-ovulatory volunteers. The $\mathrm{E}_{2}$ levels induced by the use of the nasal spray and patches reached the intended values. Unfortunately, P levels found in this study were lower than intended. Either the $\mathrm{P}$ doses administered were too low, the duration of the treatment should have been longer or the frequency of the injections should have been higher. However, the $\mathrm{P}$ levels were clearly above the physiological range. Maximum $P$ levels were reached on day 6 after the LH surge, which was also the day on which the LH levels

Table $3 P$-values of the ANOVA analysis of the $\mathrm{LH}$ serum levels in the mid-luteal phase (day $\mathrm{LH}+4$, day $\mathrm{LH}+6$, day $\mathrm{LH}+8$ and day $\mathrm{LH}+$ $10)$ in 33 volunteers randomized for either $E_{2}(600 \mu \mathrm{g}$ aerodiol every $3 \mathrm{~h}$ on the day of LH combined with 8 Fem 7 patches from day LH until $\mathrm{LH}+4$ ), $\mathrm{P}$ (progestine on the day of $\mathrm{LH}+4: 25 \mathrm{mg}$, $\mathrm{LH}+5: 100$ and $150 \mathrm{mg}, \mathrm{LH}+6: 300$ and $300 \mathrm{mg}$ ), $\mathrm{E}_{2}+\mathrm{P}$ (combination of the abovementioned regimens) or no treatment.

\begin{tabular}{lccc}
\hline & $\begin{array}{c}\text { Among the four groups } \\
(n=33)\end{array}$ & $\begin{array}{c}\mathbf{E}_{\mathbf{2}} \text { supplemented }(n=15) \text { vs } \\
\text { non-E } \text {-supplemented }(n=18)\end{array}$ & $\begin{array}{c}\text { P-supplemented }(n=17) \text { vs } \\
\text { non-P-supplemented }(n=16)\end{array}$ \\
\hline Day LH+4 & 0.26 & 0.04 & 0.76 \\
Day LH+6 & $<0.001$ & 0.16 & $<0.001$ \\
Day LH+8 & 0.88 & 0.92 & 0.68 \\
Day LH+10 & 0.15 & 0.20 & 0.11 \\
\hline
\end{tabular}




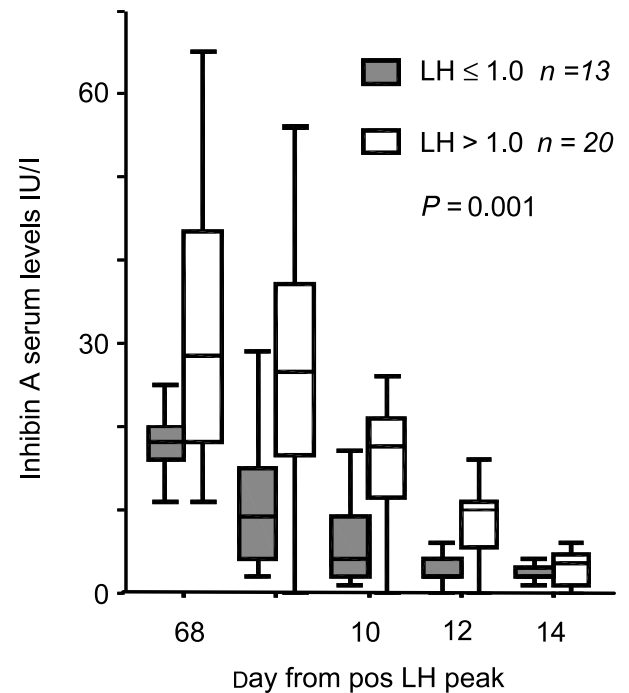

Figure 3 Box (median values and 25th and 75th percentiles) and whisker $\left(P_{5}\right.$ and $\left.P_{95}\right)$ plots representing inhibin $A$ serum concentrations in 33 subjects randomized for the administration of either high dosages of $E_{2}, P, E_{2}+P$ or no medication (controls). The inhibin A levels were analyzed separately in subjects with an $\mathrm{LH}$ level $\leq 1.0$ and $>1.0 \mathrm{lU} / \mathrm{l}$ on day 6 after the LH surge. On the $x$-axis, the days of blood sampling. pos, positive.

were significantly different between the groups. The observed LH levels in the P-supplemented groups on day 6 after the LH surge were significantly lower compared with the LH levels on day 6 after the LH surge in non-P-supplemented subjects namely 0.67 and $0.89 \mathrm{nmol} / \mathrm{l}$ vs 2.97 and $3.64 \mathrm{nmol} / \mathrm{l}(P<0.001$; see Table 3). A strong correlation was observed between $\mathrm{P}$ and LH levels on this day $(r=-0.64 ; P<0.001$; see Fig. 4). This suggests that the reached maximum $P$ levels were capable of suppressing pituitary LH release. As we were not successful in reaching the intended P levels and maintaining high levels for an extended period of time (as is the case in IVF patients), LH suppression was only achieved for 1 day. This short duration of LH suppression did not induce luteolysis, as we could not find any shortening of the luteal phase. This observation is in line with previous data, suggesting that the corpus luteum can survive without gonadotropin support for up to 3 days (39). However, despite the fact that there were no clinical signs of luteolysis, the extremely low LH concentrations on day 6 after the LH surge, resulted in an accelerated decrease to baseline of inhibin $\mathrm{A}$ in subjects with LH levels below $1 \mathrm{IU} / \mathrm{l}$.

Unfortunately, it was not possible to determine the endogenous $\mathrm{P}$ production by the corpus luteum. First, exogenously administered $\mathrm{P}$ was masking $\mathrm{P}$ production. Moreover, 17 hydroxy-progesterone was assessed as a specific marker for corpus luteum steroid biosynthesis. However, data were also obscured by the conversion of exogenous administered $\mathrm{P}$ to 17 hydroxy-progesterone. A strong correlation between $\mathrm{P}$ and $17 \mathrm{OHP}(r=0.68$,

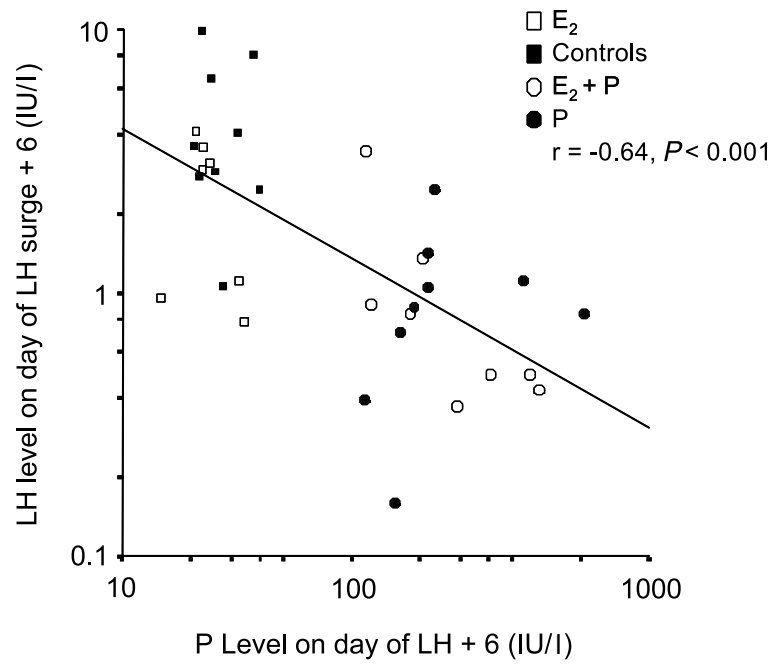

Figure 4 Scatter plot representing the correlation between $\mathrm{LH}$ and $\mathrm{P}$ serum levels on day 6 after the LH surge in 33 subjects randomized for the administration of either high dosages of $E_{2}, P, E_{2}+P$ or no medication (controls) in the early luteal phase.

$P<0.001$ ) was observed (data not shown), which may also be due to a cross-reaction in the applied assay (40).

The AUC of FSH was lower in the $\mathrm{E}_{2}$-supplemented subjects. This suggests a direct negative effect of $E_{2}$ at the pituitary gland resulting in a reduced FSH release along with a normal LH output. This is in line with earlier data from ovariectomized women (41). As expected, FSH suppression did not result in a reduction of luteal phase length.

Large differences still exist comparing the present experimental model in volunteers with IVF patients. It could be speculated that, besides the high-P levels in the early- and mid-luteal phase, additional factors are involved in eliciting advanced luteolysis after ovarian hyperstimulation for IVF. First, in IVF patients, the $E_{2}$ levels already increase during the follicular phase. In the present study, it was decided not to start the administration of $E_{2}$ in the follicular phase of the cycle, as we expected that this would suppress normal development of the follicle and subsequent ovulation. Secondly, no medication was available to induce sufficiently high and steady $\mathrm{E}_{2}$ levels immediately after administration. The intended levels could only be reached by the use of multiple patches, which unfortunately would take $12 \mathrm{~h}$ to reach maximum levels (36). To induce high$\mathrm{E}_{2}$ levels on the day of the LH surge, it was decided to add an $\mathrm{E}_{2}$ nasal spray. This would give immediate high- $\mathrm{E}_{2}$ serum levels, but followed by a rapid decrease (37).

Thirdly, evidence suggests that the ovaries also produce non-steroidal substances other than inhibins capable of blocking the positive-feedback effect of $\mathrm{E}_{2}(42)$. The production of such a substance, referred to as gonadotropin-attenuating factor (GnSAF), takes place in small antral follicles that are present in the ovaries (42). Under normal conditions, GnSAF seems to play a role in 
the regulation of the sensitivity of the pituitary gland to $\mathrm{E}_{2}$. Pituitary sensitivity increases during the late follicular phase as the production of GnSAF decreases (42) resulting in the mid-cycle LH surge. During ovarian hyperstimulation, GnSAF suppresses gonadotropin secretion both in monkeys (43) and humans (44). It could be hypothesized that in the luteal phase of IVF patients, high levels of GnSAF are still present resulting in low-LH levels and subsequent premature luteolysis.

In conclusion, we were not able to induce a shorter luteal phase in normo-ovulatory subjects by administering high doses of steroids during the early luteal phase. However, a distinct but transient suppression of midluteal LH levels could be established. This change resulted in an accelerated decrease of inhibin A indicating a 'partial' luteolysis. It could be hypothesized that we would have shortened the luteal phase length if $\mathrm{P}$ levels had been high for an extended period of time, allowing for extended LH suppression and irreversible loss of corpus luteum function. In a follow-up study, it should be possible to induce higher $\mathrm{P}$ levels for a longer period of time. However, this would not be easy as we already administer high doses of i.m. P. On the last day of $\mathrm{P}$ administration, we injected 3 ampoules of $100 \mathrm{mg} \mathrm{P}$ in $1 \mathrm{ml}$, i.e. $3 \mathrm{ml}$. Hypothetically, higher concentrations of $\mathrm{P}$ ampoules (not available on the market) should induce higher P levels.

Alternatively, altered follicular phase events such as increased production of GnSAF may also represent a possible explanation for the observed early luteolysis in IVF patients following ovarian hyperstimulation. Additional studies are required to improve the understanding of mechanisms underlying abnormal corpus luteum function after ovarian hyperstimulation.

\section{Acknowledgements}

This study was partially sponsored by Pantharhei Bioscience (Dr H J T Coelingh Bennink).

\section{References}

1 Hutchison JS \& Zeleznik AJ. The rhesus monkey corpus luteum is dependent on pituitary gonadotropin secretion throughout the luteal phase of the menstrual cycle. Endocrinology 1984115 1780-1786.

2 Filicori M, Butler JP \& Crowley WF Jr. Neuroendocrine regulation of the corpus luteum in the human, Evidence for pulsatile progesterone secretion. Journal of Clinical Investigation 198473 $1638-1647$.

3 Zeleznik AJ \& Little-Ihrig LL. Effect of reduced luteinizing hormone concentrations on corpus luteum function during the menstrual cycle of rhesus monkeys. Endocrinology $1990 \mathbf{1 2 6} 2237-2244$.

4 Maruncic M \& Casper RF. The effect of luteal phase estrogen antagonism on luteinizing hormone pulsatility and luteal function in women. Journal of Clinical Endocrinology and Metabolism 198764 148-152.

5 Duffy DM, Stewart DR \& Stouffer RL. Titrating luteinizing hormone replacement to sustain the structure and function of the corpus luteum after gonadotropin-releasing hormone antagonist treatment in rhesus monkeys. Journal of Clinical Endocrinology and Metabolism 199984 342-349.
6 Zeleznik AJ. In vivo responses of the primate corpus luteum to luteinizing hormone and chorionic gonadotropin. PNAS 199895 11002-11007.

7 Soules MR, Steiner RA, Clifton DK, Cohen NL, Aksel S \& Bremner WJ. Progesterone modulation of pulsatile luteinizing hormone secretion in normal women. Journal of Clinical Endocrinology and Metabolism 198458 378-383.

8 Gibson M, Nakajima ST \& McAuliffe TL. Short-term modulation of gonadotropin secretion by progesterone during the luteal phase. Fertility and Sterility $1991 \mathbf{5 5} 522-528$.

9 Casper RF \& Yen SS. Induction of luteolysis in the human with a long-acting analog of luteinizing hormone-releasing factor. Science $1979205408-410$.

10 Mais V, Kazer RR, Cetel NS, Rivier J, Vale W \& Yen SS. The dependency of folliculogenesis and corpus luteum function on pulsatile gonadotropin secretion in cycling women using a gonadotropin-releasing hormone antagonist as a probe. Journal of Clinical Endocrinology and Metabolism 198662 1250-1255.

11 Edwards RG, Steptoe PC \& Purdy JM. Establishing full-term human pregnancies using cleaving embryos grown in vitro. British Journal of Obstetrics and Gynaecology 198087 737-756.

12 Jones HW Jr. What has happened? Where are we? Human Reproduction 199611 (Suppl 1) 7-24.

13 Huirne JA, Lambalk CB, van Loenen AC, Schats R, Hompes PG, Fauser BC \& Macklon NS. Contemporary pharmacological manipulation in assisted reproduction. Drugs 200464 297-322.

14 Smitz J, Van Den Abbeel E, Bollen N, Camus M, Devroey P, Tournaye H \& Van Steirteghem AC. The effect of gonadotrophinreleasing hormone (GnRH) agonist in the follicular phase on in-vitro fertilization outcome in normo-ovulatory women. Human Reproduction 19927 1098-1102.

15 Smith EM, Anthony FW, Gadd SC \& Masson GM. Trial of support treatment with human chorionic gonadotrophin in the luteal phase after treatment with buserelin and human menopausal gonadotrophin in women taking part in an in vitro fertilisation programme. British Medical Journal 1989298 1483-1486.

16 Soliman S, Daya S, Collins J \& Hughes EG. The role of luteal phase support in infertility treatment: a meta-analysis of randomized trials. Fertility and Sterility 199461 1068-1076.

17 Aboulghar MA \& Mansour RT. Ovarian hyperstimulation syndrome: classifications and critical analysis of preventive measures. Human Reproduction Update 2003 9 275-289.

18 Penzias AS. Luteal phase support. Fertility and Sterility $2002 \mathbf{7 7}$ 318-323.

19 Pritts EA \& Atwood AK. Luteal phase support in infertility treatment: a meta-analysis of the randomized trials. Human Reproduction $2002172287-2299$.

20 Smitz J, Erard P, Camus M, Devroey P, Tournaye H, Wisanto A \& Van Steirteghem AC. Pituitary gonadotrophin secretory capacity during the luteal phase in superovulation using GnRH-agonists and HMG in a desensitization or flare-up protocol. Human Reproduction 19927 1225-1229.

21 Beckers NG, Laven JS, Eijkemans MJ \& Fauser BC. Follicular and luteal phase characteristics following early cessation of gonadotrophin-releasing hormone agonist during ovarian stimulation for in-vitro fertilization. Human Reproduction 200015 43-49.

22 Donderwinkel PF, Schoot DC, Pache TD, de Jong FH, Hop WC \& Fauser BC. Luteal function following ovulation induction in polycystic ovary syndrome patients using exogenous gonadotrophins in combination with a gonadotrophin-releasing hormone agonist. Human Reproduction 19938 2027-2032.

23 Ditkoff EC, Cassidenti DL, Paulson RJ, Sauer MV, Paul WL, Rivier J, Yen SS \& Lobo RA. The gonadotropin-releasing hormone antagonist (Nal-Glu) acutely blocks the luteinizing hormone surge but allows for resumption of folliculogenesis in normal women. Amarican Journal of Obstetrics and Gynecology 1991165 1811-1817.

24 Frydman R, Cornel C, de Ziegler D, Taieb J, Spitz IM \& Bouchard P. Prevention of premature luteinizing hormone and progesterone rise with a gonadotropin-releasing hormone antagonist, Nal-Glu, in controlled ovarian hyperstimulation. Fertility and Sterility 1991 $56923-927$. 
25 Elter K \& Nelson LR. Use of third generation gonadotropin-releasing hormone antagonists in in vitro fertilization-embryo transfer: a review. Obstetrical and Gynecological Survey 200156 576-588.

26 Ragni G, Vegetti W, Baroni E, Colombo M, Arnoldi M, Lombroso G \& Crosignani PG. Comparison of luteal phase profile in gonadotrophin stimulated cycles with or without a gonadotrophin-releasing hormone antagonist. Human Reproduction $2001162258-2262$.

27 Albano C, Grimbizis G, Smitz J, Riethmuller-Winzen H, Reissmann T, Van Steirteghem A \& Devroey P. The luteal phase of nonsupplemented cycles after ovarian superovulation with human menopausal gonadotropin and the gonadotropin-releasing hormone antagonist Cetrorelix. Fertility and Sterility 1998 70 357-359.

28 Beckers NG, Macklon NS, Eijkemans MJ, Ludwig M, Felberbaum RE, Diedrich K, Bustion S, Loumaye E \& Fauser BC. Nonsupplemented luteal phase characteristics after the administration of recombinant human chorionic gonadotropin, recombinant luteinizing hormone, or gonadotropin-releasing hormone (GnRH) agonist to induce final oocyte maturation in in vitro fertilization patients after ovarian stimulation with recombinant follicle-stimulating hormone and GnRH antagonist cotreatment. Journal of Clinical Endocrinology and Metabolism $2003 \mathbf{8 8} 4186-4192$.

29 Tavaniotou A, Albano C, Smitz J \& Devroey P. Comparison of LH concentrations in the early and mid-luteal phase in IVF cycles after treatment with HMG alone or in association with the $\mathrm{GnRH}$ antagonist Cetrorelix. Human Reproduction 200116 663-667.

30 Fauser BC \& Devroey P. Reproductive biology and IVF: ovarian stimulation and luteal phase consequences. Trends in Endocrinology and Metabolism 200314 236-242.

31 Miyake A, Tanizawa O, Aono T, Yasuda M \& Kurachi K. Suppression of luteinizing hormone in castrated women by the administration of human chorionic gonadotropin. Journal of Clinical Endocrinology and Metabolism $1976 \mathbf{4 3} 928-932$.

32 Hohmann FP, Laven JS, de Jong FH, Eijkemans MJ \& Fauser BC. Low-dose exogenous FSH initiated during the early, mid or late follicular phase can induce multiple dominant follicle development. Human Reproduction 200116 846-854.

33 Van Der Gaast MH, Beckers NG, Beier-Hellwig K, Beier HM, Macklon NS \& Fauser BC. Ovarian stimulation for IVF and endometrial receptivity - the missing link. Reproductive Biomedicine Online 20025 (Suppl 1) 36-43.

34 Tavaniotou A, Albano C, Smitz J \& Devroey P. Effect of clomiphene citrate on follicular and luteal phase luteinizing hormone concentrations in in vitro fertilization cycles stimulated with gonadotropins and gonadotropin-releasing hormone antagonist. Fertility and Sterility 200277 733-737.
35 van Santbrink EJ, Hop WC, van Dessel TJ, de Jong FH \& Fauser BC. Decremental follicle-stimulating hormone and dominant follicle development during the normal menstrual cycle. Fertility and Sterility $19956437-43$.

36 Geyer D, Gerrits MG, Renoux A \& Uhl W. Pharmacokinetics of Fem7, a once-weekly, transdermal oestrogen replacement system in healthy, postmenopausal women. Gynecologic and Obstetric Investion $1999 \mathbf{4 8} 1-6$.

37 Devissaguet JP, Brion N, Lhote O \& Deloffre P. Pulsed estrogen therapy: pharmacokinetics of intranasal 17-beta-estradiol (S21400) in postmenopausal women and comparison with oral and transdermal formulations. European Journal Drug Metabolism and Pharmacokinets 199924 265-271.

38 Devroey P, Palermo G, Bourgain C, Van Waesberghe L, Smitz J \& Van Steirteghem AC. Progesterone administration in patients with absent ovaries. International Journal of Fertility 198934 188-193.

39 Hutchison JS \& Zeleznik AJ. The corpus luteum of the primate menstrual cycle is capable of recovering from a transient withdrawal of pituitary gonadotropin support. Endocrinology $19851171043-1049$.

40 de Jong FH, Mallios C, Jansen C, Scheck PA \& Lamberts SW. Etomidate suppresses adrenocortical function by inhibition of 11 beta-hydroxylation. Journal of Clinical Endocrinology and Metabolism 198459 1143-1147.

41 Messinis IE, Milingos S, Alexandris E, Mademtzis I, Kollios G \& Seferiadis K. Evidence of differential control of FSH and LH responses to GnRH by ovarian steroids in the luteal phase of the cycle. Human Reproduction 200217 299-303.

42 Messinis IE. Modulatory effect of the ovary on LH secretion. Annals of the New York Academy of Sciences 2003997 35-41.

43 Schenken RS \& Hodgen GD. Follicle-stimulating hormone induced ovarian hyperstimulation in monkeys: blockade of the luteinizing hormone surge. Journal of Clinical Endocrinology and Metabolism 1983 57 50-55.

44 Messinis IE \& Templeton AA. Endocrine and follicle characteristics of cycles with and without endogenous luteinizing hormone surges during superovulation induction with pulsatile follicle-stimulating hormone. Human Reproduction 19872 11-16.

Received 12 January 2006

Accepted 3 May 2006 